\title{
Laying Foundation to Advertisement Genre: An Analysis of Job Advertisement Discourse Made by the Royal Civil Service Commission of Bhutan
}

\author{
Pema Dendup \\ Yadi Central School, Yadi, Bhutan \\ peeedendup@gmail.com
}

\section{ARTICLE HISTORY \\ Received : 30 December 2020 \\ Revised : 19 January 2021 \\ Accepted : 22 February 2021}

\section{KEYWORDS}

Genre Analysis

Job Advertisement

Announcement

Discourse

Community

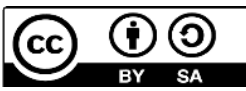

\begin{abstract}
To lay foundation in the literature related to the genre of advertisements, this paper is a synchronic approach to study the job advertisements made by the Royal Civil Service Commission (RCSC) of Bhutan. RCSC is the major recruiting agency of civil servants into a government job. As mandated, RCSC recruits thousands of fresh employees annually. RCSC features its job-related announcements in the media, mainly the Bhutan Broadcasting Service, the mainstream media and also in its official website. The data of this study was the 'Vacancy Announcement' dated January 8, 2020, featured in RCSC website and the analysis of the data was based on Swale's (1990) Six Defining Characteristics of Discourse Community. The results showcased Bhutan as a bilingual society for informing the citizens as the job advertisements were delivered in both Dzongkha and English. RCSC's format of job advertisement employed the common format used by most of the organisations. This study points that there is a need to look into some elements used by other organisations. Therefore, this study recommends RCSC, as the major recruiting agency in Bhutan, to incorporate other missing elements of job advertisement.
\end{abstract}

\section{Introduction}

The abbreviation RCSC stands for Royal Civil Service Commission (henceforth RCSC). Bhutan Civil Service Rules (henceforth BCSR) (2012) states that it was instituted in pursuance of Article 26 of the Constitution of the Kingdom of Bhutan, the Royal Charter of the Royal Civil Service Commission in 1982. Its vision is "A dynamic and professional civil service committed to promoting good governance in pursuit of Gross National Happiness." As the vision states, it is the commission that takes charge of all the civil servants in the country, promoting good governance. This divulges the common public goals, which Swales (1990) considers as one of the important characteristics. According to the Civil Service Act of Bhutan (2010), civil service values are accountability, honesty, impartiality, integrity, leadership, loyalty, openness, professionalism and selflessness.

As stated above, RCSC has certain goals and values which the discourse community works collaboratively towards achieving its goals. To achieve their common goals, the commission has professionals, working under it. Its organogram shows the chairman, the four Commissioners, and a Director, to mention a few, as the members in the discourse community. This clearly shows that the discourse community member is varied; and the success or the failure of the community will depend on their collaboration.
In the process of conducting this study, it was revealed that there had been hardly any research attempt related to this genre, which indicates that the particular genre is not considered as an important genre. Much of the literature is understandably more focused on the contents or trends of job advertisements (Askehave, 2010; Gerek \& Efeoglu, 2015; Kaba, 2017; Walker et al., 2008). The qualifications and skills that are specifically sought within certain professions have been explored (Brooks, Greer, \& Morris, 2018; Choi \& Rasmussen, 2009), as well as analysing the employability chances of graduates from a particular university program (Omar et al., 2012; Sari et al., 2018). Therefore, this study will lay some foundation in providing some contributions to the literature related to advertisement genre and aid in conducting further research in the future.

This analysis of job advertisement, commonly known as 'vacancy announcement' in Bhutan, is one important aspect of genre used by the commission, which is considered as a discourse community. The genre is used as a tool to recruit new memberships into the community as discourse participants never stay the same. It is dynamic, so the analysis of the findings is based on its purpose, structure, language features, discourse community, as well as psychological and sociological features.

\section{Literature Review}

A genre is a recognizable communicative event that is characterized by a set of communicative purposes. According to Bhatia (1993), these purposes are mutually 
understood by the regular members of the community. Most often it is highly structured and conventionalized with constraints on allowable contributions in terms of their intent, positioning, form and functional value. Although, these constraints are often exploited by the expert members of the discourse community to achieve their personal desires. Similarly, "a genre comprises a class of communicative events, the members of which must share some set of communicative purposes. These purposes are recognized by the expert members of the parent discourse community, and thereby constitute the rationale for the genre. The rationale shapes the schematic structure of the discourse and influences and constraints choice of content and style" (Swales, 1990, p. 58). Fairclough (1995) defines the genre as "a use of language associated with and constituting part of some particular social practice, such as interviewing people (interview genre) or advertising commodities (advertising genre)." A genre can be described in terms of its organizational properties-an interview, for instance, is structured in a quite different way from an advertisement. Berkenkotter \& Huckin (1993) had proposed five general principles that characterises genre:

a. Dynamism. Genre is not static, but dynamic rhetorical forms that develop from responses to recurrent situations and serve to stabilize experience and give it coherence and meaning. Genres change over time in response to their users' socio-cognitive needs.In other words, genre is constantly transforming or it evolves with time as per the requirement of the society. Some genres occur frequently, but there are genres with few occurences.

b. Situatedness. Current knowledge of the genre is derived from and embedded in the participation in the communicative activities of daily and professional life.

c. Form and Content. Genre knowledge includes a sense of what content is appropriate to a particular purpose in a particular situation at a particular point in time. Genres vary in their form and content. A job advertisement as a genre differs in both form and content from other genres.There is a allowable variation between different examples of a genre. Some moves of a genre are obligatory while others are optional.

d. Duality of Structure. As we use genre rules to engage in professional activities, we constitute social structures and simultaneously reproduce these structures. Like language, which comprises two sets of structure, genres also have duality in their structure. The ways genres are formed are affected by the social occasion and the goals and purposes of the participants. In other words, the producers and consumers of the discourse community affects the structure.

e. Community Ownership. Genre conventions signal a discourse community's norms, ways of knowing, etc. Genre analysis on 'Danish job advertisements: Increasing in complexity' by Walters \& Fage-Butler
(2014) state that within human resource management literature, job advertisements are not tackled as a generic unit, meaning that one rarely finds information about all the sections that are included in a job advertisement.

Rafaeli \& Oliver (1998) identified a "skeleton" that most job advertisements have in common. The skeleton consists of four elements: 1) an organizational identity, 2) its human resources needs, 3) information about what is required to fulfill these needs, and 4) information about how to contact the organization. These elements, according to Rafaeli \& Oliver (1998), form the basis of employment advertisements. Job advertisements can, of course, be enriched with additional information about the organization doing the hiring, such as its values/culture.

According to Bratton \& Gold (2007) a typical format for a job description contains seven elements which are: 1) job title, 2) department, 3) responsible to, 4) relationships, 5) purpose of job/overall objectives, 6) specific duties and responsibilities and 7) physical/economic conditions ( $\mathrm{p}$. 253-254). Marchington \& Wilkinson's (2007) format for job descriptions shares some of the same elements found in Bratton and Gold's format but with some differences. Their format includes nine elements which are: "1) Job title, 2) location, 3) responsible to, 4) responsible for, 5) the main purpose of the job, 6) responsibilities/duties, 7) working conditions, 8) other matters and 9) any other duties"

The review of various works of literature highlights the variations in the format of a job advertisement. The variation is significantly observed in the discourse structure.

\section{Method}

This study is a synchronic approach, looking at job announcement of the year 2018, made by the RCSC, on January 8, 2020. Patton's (2002) criterion sampling was used to select the job announcements. The data for this study was collected by employing two criteria.The two criteria used during the criterion sampling phase were to consider only the job announcements made by the RCSC and to give a job announcement for a full-time position only.

\section{Results}

The analysis was performed for data collected from the RCSC website (www.rcsc.gov.bt.) by employing Swales (1990) six defining features of a discourse community.

\subsection{The Communicative Purpose of the Genre}

According to Swales (1990), a genre comprises a class of communicative events, the members of which must share some set of communicative purposes. This purpose is recognized by the expert members of the parent discourse community, and thereby constitutes the rationale for the genre. The rationale shapes the schematic structure of the discourse and influences and constraints choice of content and style," (p. 58). Bhatia (1993) explains a genre as a 
recognizable communicative event characterized by a set of communicative purpose(s) identified and mutually understood by members of the professional or academic community in which it regularly occurs. Most often it is highly structured and conventionalized with constraints on allowable contributions in terms of their intent, positioning, form and functional value. These constraints, however, are often exploited by the expert members of the discourse community to achieve private intentions within the framework of socially recognized purpose(s) (p. 13).

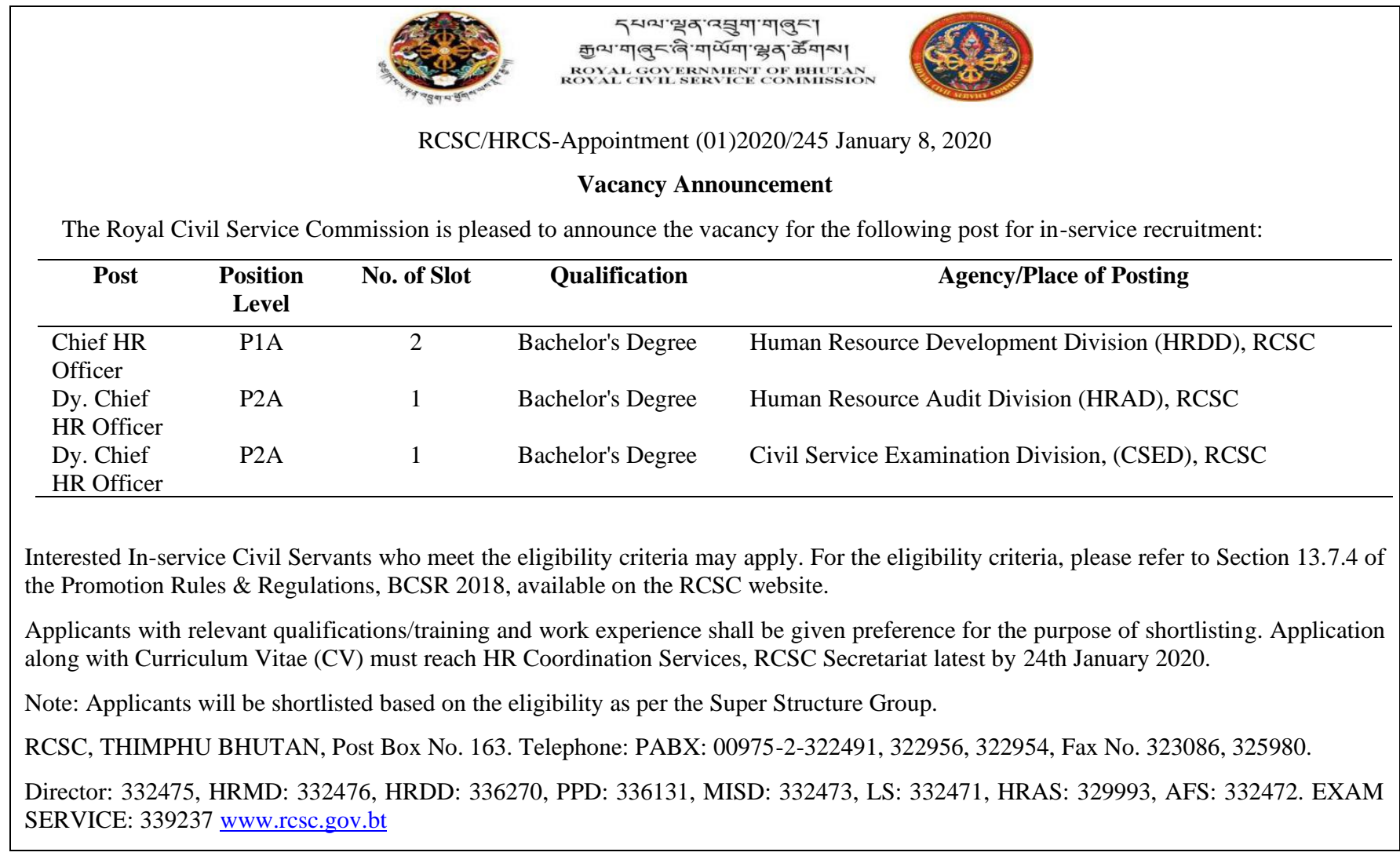

Figure 1. RCSC Vacancy Announcement on January 8, 2020

Figure 1 shows a vacancy was announced by the Royal Civil Service Commission of Bhutan on 8 January 2020 to communicate the availability of vacancies under the commission. This genre's communicative purpose is to notify those eligible in-service civil servants about the availability of slots

\subsection{The Discourse Community}

RCSC is the producer and the consumers are the eligible in-service civil servants. The relationship is an employeremployee relationship because it happens between the organization which provides job and the other, who are looking for jobs. The job vacancy announcement was featured online on the website www.rcsc.gov.bt on January 8,2020 . The commission's purpose was to get the right candidates for the vacant posts, without which, the community would be deprived of an adequate number of members. RCSC consists of varied professional members in terms of qualification, work experience, novices and experts working under it. Its organogram shows a range from legal services, administration and finance services, and HR audit service and directors, other commissioners till the chairman.

Swales (1990) states that a discourse community has a common set of public goals and goals may be formally inscribed in documents. In this context, the RCSC of Bhutan also works towards achieving its common goals as inscribed in the BCSR. Its members are guided by its rules and regulations. In the foreword to BCSR (2012), it states that RCSC will provide even more fair, transparent, accountable and effective uniform rules and regulations in managing the civil service of Bhutan. Its vision states that "A dynamic and professional civil service committed to promoting good governance in pursuit of Gross National Happiness." Therefore, there is a common goal they strive to achieve. A discourse community has mechanisms of intercommunication among its members. The participatory mechanisms will vary according to the community (Swales, 1990, p. 25). The participatory mechanism mostly happens at meetings, correspondences, notices, and telecommunications. 
Table 1. Discourse Structure of the Vacancy Announcement

\begin{tabular}{|c|c|c|}
\hline No & Moves & Move Descriptions \\
\hline 1 & Logo & $\begin{array}{l}\text { The logo of RCSC is well printed, showing the identity of the agency. Its name has been inscribed } \\
\text { in both English and Dzongkha. The move is obligatory. }\end{array}$ \\
\hline 2 & Date & $\begin{array}{l}\text { The date of the announcement (January } 8,2020 \text { ) is an obligatory move here, so that, the eligible } \\
\text { candidates know about the time of the announcement. }\end{array}$ \\
\hline 3 & Title & $\begin{array}{l}\text { The title "Vacancy Announcement" is very important here as it gives quick information on the } \\
\text { genre. It is an obligatory move. }\end{array}$ \\
\hline 4 & Details of announcement & $\begin{array}{l}\text { Details include post, position level, number of the slot, qualification, and agency/place of posting. } \\
\text { It is an obligatory move because it gives the main information about the vacancy. }\end{array}$ \\
\hline 5 & Intertextual reference & $\begin{array}{l}\text { Here, it gives an inter-textual reference (Section } 13.7 .4 \text { of BCSR 2018) to the eligibility criteria } \\
\text { which will make the announcement more reliable and accurate. Therefore, it is an obligatory move. }\end{array}$ \\
\hline 6 & Required documents & $\begin{array}{l}\text { Information on the requirement of necessary documents (For example, a CV) is very important and } \\
\text { the move here should be obligatory. }\end{array}$ \\
\hline 7 & Contact details & $\begin{array}{l}\text { The genre mentions the website, the office telephone number for the eligible candidates to clarify } \\
\text { and seek further clarifications. }\end{array}$ \\
\hline
\end{tabular}

\subsection{The Discourse Structure}

The vacancy announcement contained many information, all of which can be described as moves within the discourse structure.

\subsection{Important Language Features}

Fisk (1987, cited in Candler, 2000) sees the genre as a means of constructing both the audience and reading subject. In this genre, the RCSC after constructing the type of audience has used a common sense that is 'is pleased' which is used in formal writing. It shows that this is a formal job announcement. A word choice like 'pleased' has a great impact on the readers because it is pleasing to ears, so that, the applicants would firstly love to read the announcement and wish to apply for the posts.

This announcement also specifies by using the adjective 'interested' in-service civil servants. Its aim to attract only the right candidates for the post and not all civil servants are eligible for application. In doing this, the discourse community also employs abbreviations such as RCSC, HRC, HRDD, HR, HRMD, BCSR, etc.

\subsection{Sociological Features}

This genre is set in a bilingual society as depicted by the use of Dzongkha and English in its logo, and a bilingual statement of the name Royal Civil Service Commission. The genre has used English as a medium of communication to the eligible candidates, showing a type of society where English is mostly used and the dominance of the English language as the language of official communication. Dzongkha, the national language is used very little compared to English. It gives a vivid picture of a language that the discourse community uses.

It also talks about a close-knit society, which is an IT literate modern society, because the announcement was made online and the interested applicants were asked to have access to the website www.rcsc.gov.bt to get more information. It also shows that telecommunication facilities are well developed.

\subsection{Psychological Features}

The genre has firstly used its attractive logo, with the name written both in Dzongkha and English, using capital letters in bold. As the aforementioned says, the use of the phrase 'is pleased' sounds so formal and pleasing. The emphasis has been made by making the title in bold letters and by underlining it.

The next is the use of a graphic organizer, putting down sub-headings about the vacant posts by mentioning them in table format, categorizing them into different columns, which can be easily read and understood by the readers. One tactic, like in the above, is bolding the main topics such as SL.No, Ministry/Agency, Position Title and Position level. These are the main pieces of information, the applicants must know about the posts. Likewise, section 13.7.4 has been bolded so that, the eligible candidates can see the inter-textual reference made and the most important point worthy of note is the 'date of submission' which has been bolded, letting to feel the importance of the timely application. To make the candidates know about the post in detail, they are provided with the website and telephone number, which the applicants can get connect and make inquiries about the job vacancy.

\section{Discussion}

To Rafaeli \& Oliver (1998), an organizational identity, its human resources needs, information about what is required to fulfill these needs and information about how to contact the organization are the common skeleton of job announcements. Does RCSC follow a similar format? Based on the analysis, RCSC uses the $\log$ o on both top corners. Beautiful logos are attractively designed both in Dzongkha and English with its organisational identity, which showcases Bhutan as a bilingual society. It has the date and the title which are the mandatory moves. The details of the announcement include the post, position level, No. of the slot, qualification, and agency/place of posting). It has the human resource needs, required documents, intertextual reference and its contact details. In light of the 
common format, RCSC uses the similar format which most of the organizations use. There is no mentioning of intertextual reference by Rafaeli \& Oliver which RCSC takes it as a mandatory move in the announcement.

The common format followed by RCSC is deprived of 3 elements given by Bratton and Gold (2007). RCSC considers 1) relationships, 2) purpose of job/overall objectives, 3) specific duties and responsibilities and 4) physical/economic conditions, which Bratton \& Gold (2007) treat as mandatory move as optional move. The purpose of job/overall objectives is not explicitly stated though it is implied in the job position and similarly, specific duties and responsibilities are also not clearly stated. A 'physical/economic condition' related to the position announced is one element worthy of note, as it is far from the mentioning in the announcement. Marchington \& Wilkinson's (2007) put this as 'working conditions'. Should RCSC mention 'the physical and economic conditions, the job seeker of relevant qualification and aptitude' it will understand the reality of the work environment and their earning which will also determine their interest at the very initial stage.

RCSC does not incorporate two elements from Marchington \& Wilkinson's (2007) format. The format encompasses 9 elements. 'Other matters' and 'any other duties' are two optional moves from Marchington \& Wilkinson's format which RCSC should look into the requirement of the elements in the job announcement hereafter.

\section{Conclusion}

This synchronic approach to analysis of genre the 'job advertisement' concluded that a genre has form, content, and language features employed to fulfill the communicative purpose. This genre uses formal language, which is suitable to the readers of the related community and this shows that a genre constructs its audience and the reading subject. The job advertisement genre focuses on the use of only the main and necessary information. In other words, the moves in the genre are mostly obligatory, showing its characteristics as a different genre.

A genre can be described in terms of organization properties. A vacancy announcement is certainly a typical type of genre. It has different structures and properties which depend on its communicative purposes. The main purpose of this genre, to restate, is to convey information about the availability of job vacancies in the discourse community.

The findings of this paper are based on synchronic analysis of a single format of job announcement; therefore, the findings of this research cannot be generalized. A bigger sampling and comparative analysis could have been undertaken for the reliability or a diachronic approach of analysis could have initiated for a larger sampling. This study suggests a study on a larger scale to study employing both synchronic and diachronic approaches. However, this study provides a varying components of a job advertisement format and suggests for a unananimous and a comprehensive format.

\section{References}

Askehave, I. (2010). Communicating leadership: A discourse analytical perspective on the job advertisement. The Journal of Business Communication (1973), 47(3), 313-345.

Berkenkotter, C., \& Huckin, T. N. (1993). Rethinking genre from a sociocognitive perspective. Written communication, 10(4), 475-509.

Bhatia, V. K. (1993). Analysing Genre: Language Use in Professional Settings. Longman.

Bhutan Civil Service Rules and Regulation. (2012). Bhutan Civil Service Rules and Regulation, 6th Edition. Royal Government of Bhutan, Thimphu, Bhutan.

Bratton, J., \& Gold, J. (2007). Human Resource Management: Theory and Practice, 4th Edition. Palgrave Macmillan.

Brooks, N. G., Greer, T. H., \& Morris, S. A. (2018). Information systems security job advertisement analysis: Skills review and implications for information systems curriculum. Journal of Education for Business, 93(5), 213-221.

Chandler, D. (1997). An Introduction to Genre Theory. Retrieved on 7th March 2015 from http://www.aber.ac.uk/media/Documents/intgenre/ch andler_genre_theory.pdf

Choi, Y., \& Rasmussen, E. (2009). What qualifications and skills are important for digital librarian positions in academic libraries? A job advertisement analysis. The journal of academic librarianship, 35(5), 457-467.

Fairclough, N. (1995). Language \& Power. Longman.

Gerek, I. H., \& Efeoglu, I. E. (2015). What qualifications and skills are important for civil engineers? A job advertisement analysis. In Proceedings of the MakeLearn and TIIM: oint International Conference (pp. 689-695).

Kaba, A. (2017). Online library job advertisement in United Arab Emirates: a content analysis of online sources. Library Management.

Marchington, M., \& Wilkinson, A. (2007). Human resource management at work: People management and development. $3^{\text {rd }}$ Edition. Chartered Institute of Personnel and Development.

Omar, N. H., Manaf, A. A., Mohd, R. H., Kassim, A. C., \& Abd Aziz, K. (2012). Graduates' employability skills 
based on current job demand through electronic advertisement. Asian Social Science, 8(9), 103.

Patton, M. Q. (2002). Qualitative Research \& Evaluation Methods, 3rd edition. Sage Publications Incorporated.

Rafaeli, A., \& Oliver, A. L. (1998). Employment ads. Journal of Management Inquiry, 7(4): 342.

Royal Civil Service Commission. (2012). Bhutan Civil Service Rules and Regulation. Royal Government of Bhutan.

Sari, R., Putri, S. E., Herdi, H., \& Hamuddin, B. (2018). Bridging critical discourse analysis in media discourse studies. Indonesian EFL Journal, 4(2), 8089.

Swales, J. M. (1990). Genre Analysis- English in Academic and Research Settings. Cambridge University Press.

Walker, H. J., Feild, H. S., Giles, W. F., \& Bernerth, J. B. (2008). The interactive effects of job advertisement characteristics and applicant experience on reactions to recruitment messages. Journal of Occupational and Organizational Psychology, 81(4), 619-638.

Walters, N. L., \& Fage-Butler, A. M., (2014). Danish job advertisements: Increasing in complexity. Communication \& Language at Work (CLAW). 